\title{
SUPPORT STRUCTURE DESIGN FOR NEW ZEALAND FOREST PRODUCTS LTD'S NO. 5 RECOVERY BOILER
}

\author{
R. D. Sharpe *
}

Presented at the Pacific Structural Steel Conference, Auckland, August 1986

\begin{abstract}
SYNOPSIS
Internationally, the seismic resistance of large industrial boilers appears to be addressed by the most simple application of relatively low equivalent static lateral forces which are resisted elastically. This p a p er describes measures taken to ensure a predictable and controlled seismic performance of such a boiler during a major earthquake. Inelastic time-history methods of analysis were used to confirm that the desired perforamce would be achieved. As a result the client was able to purchase a relatively standard boiler in the international marketplace and still achieve a level of seismic resistance consistent with the best NZ practices.
\end{abstract}

\section{INTRODUCTION}

New Zealand Forest Products No. 5 Recovery Boiler is a large steam generator of similar size and form to the largest of those installed in thermal power stations. The slag, unlike that of a fossil-fuelled boiler, forms a molten heap. Any failure of the boiler which causes water to be dumped onto this slag may lead to the regeneration of sufficient steam to create a catastrophic explosion. Controlled earthquake performance is therefore important to the owner provided this can be achieved without unreasonable cost. To allow for its large thermal expansion, the 1500 tonne boiler is hung from the roof beams of a $50 \mathrm{~m}$ high steel support structure. It is normal to guide such a boiler laterally (while allowing vertical sliding at the guides) at a small number of positions up the boiler height. The external frames of this structure are cross-braced to provide lateral strength. Industry practice has been to force the boiler and its supporting structure to move horizontally together during a large earthquake by providing laterally strong and rigid guides. In general, as boilers are much stiffer than the supporting structures, it could be expected that the boiler would act as a seismic lateral load-resisting element until either the lateral guides or the boiler failed. In a move that appears to be without precedent elsewhere, the lateral guides have been deliberately detailed to yield at predictable load levels and the support structure design has then been based on analyses which accurately take this into account. By choosing to adopt this approach the owner has been able to take advantage of the cost saving of installing a boiler generally the same as those manufactured for less seismic regions of the world and therefore available competitively, and at the same time achieve controlled earthquake

* Associate, Beca Carter Hollings \& Ferner Ltd, Consulting Engineers, Wellington. performance with damage expected to be limited to sacrificial members, i.e. the boiler guides.

CONCEPTUAL DESIGN AND BOILER PROCUREMENT

It was BCHF's previous experience with such boiler/structures tendered from overseas that most boiler suppliers proposed structural support solutions which did not adequately address the seismic resistance aspects. The client's project management and engineering team asked $\mathrm{BCHF}$, as structural consultants, to assist in this aspect of the tender specification.

Earthquake simulation analyses carried out by BCHF at this time were used as the basis for seismic load and clearance information included in the tender specification. Design-supply tenderers for the boiler were required to offer a support structure layout capable of being designed in accordance with the specified design philosphy. They had the option of also offering to supply the support structure itself.

The design philosophy (i.e. the intention to isolate partially the boiler within the structure) appeared in the tender specification. Following evaluation of the support structure layouts offered by tenderers the owner decided to award the supply of the boiler to Combustion Engineering of Canada and commissioned $\mathrm{BCHF}$ to complete detailed design for a cross-braced structural steel support structure following the agreed philosophy.

\section{FINAL DESIGN BRIEF}

To meet the overall timetable for the project it was necessary to produce sufficient information to indent the main steel members within six weeks of being commissioned.

Therefore to meet the time restraints and the design philosophy concurrently it 
was decided that the support structure should be proportioned so as to resist without damage (except to the yielding boiler guides) earthquakes within a return period of 1000 years. Because of the small risk of such an earthquake occurring during the life of the plant and because of the partial isolation of the boiler from the support structure when the guides yield, it was furthermore decided that a full capacity design of the support structure would be unnecessary. This approach had the double advantage of reducing the complexity of the design process while ensuring that the structure, in remaining elastic to a higher than normal level of earthquake loading, would remain virtually undamaged even in a major earthquake. At the same time the boiler guides would be proportioned to accept all the imposed deformations in a controlled manner and thus keep relative movements between boiler and support frame within acceptable limits.

If the boiler and support structure system would remain substantially elastic during a strong earthquake then the seismic lateral loading could be determined by distributing the design base shear up the height of the structure by either a manual method or by recourse to spectral modal analysis. However, the presence of the yielding guides meant that these methods would not be sufficiently valid and the more appropriate technique would be to subject an analytical model of the frame to records of several earthquakes which were representative of the 1000 year return period event using the "time-history" method. An envelope of the maximum member forces and displacements could then be found, by taking worst values from the results of each of the several earthquakes applied.

The specification of the 1000 year return period earthquake for the site of the boiler (Kinleith) was assembled by using skills and computer programs developed by $\mathrm{BCHF}$ over several years.

From a catalogue of recorded strong motions four were chosen which were likely to have the greatest effect on the boiler support structure and which could also be considered consistent with the local site conditions. These records were scaled to be consistent with the parameters established in the risk study.

They were:

\section{Scaling Factor}

(i) San Fernando: Pacioma Dam,

(ii) Imperial Valley, El Centro, May $191940 \mathrm{~N}-\mathrm{S} * 1.5$

(iii) Imperial Valley, El Centro, May $191940 \mathrm{E}-\mathrm{W}$ $\star 2.4$

(iv) Eureka : Eureka Federal Building, Dec 211954 NIIW * 2.5

\section{DETAILED ANALYSIS AND DESIGN}

Two-dimensional analytical models were set up to represent one of each of the two exterior cross-braced frames in each principal direction. Vertical support for the boiler is provided mainly by frames without lateral resistance. Preliminary studies showed that the tube effect was not significant enough to invalidate the twodimensional treatment. The boiler was modelled as a series of equivalent beams positioned on the centrelines of the boiler elevation. The appropriate mass was lumped at a number of positions on the boiler and at each level on the exterior frames. Members capable of simple inelastic behaviour in both tension and compression were included to model both the ductile boiler guides and the vertical hangers supporting the boiler.

Each frames was subjected to an elastic time-history analysis for the four different earthquake records. For each earthquake, plots of each guide force versus time were obtained and ductility demand assessed to enable appropriate detailing. The guides are intended to be replaced after a major earthquake. Similarly the relative deformations of boiler and support frame were monitored to enable the process engineers to check that important pipelines, controls and ducts could endure their magnitude and number of cycles imposed. For all structural members, envelopes of maximum forces were produced to enable their elastic design to be checked.

\section{CONCLUSION}

By the above process the client's objectives were achieved namely:

- use of a standard boiler design with resulting cost saving.

- good protection against possible boiler damage in a major earthquake.

- a support structure which can be expected to be undamaged in a major earthquake.

damage to process lines controlled and limited.

- structural damage limited in the main to the boiler guides which are items readily replaceable.

\section{ACKNOWLEDGEMENTS}

The permission of Mr Victor Jowsey, Chief Engineer, New Zealand Forest Products Ltd, to present this report is appreciated.

The work described here was a joint effort carried out by a large number of individuals within the NZFP Ltd Project Management/Engineering teams in Auckland and Kinleith and in both the Auckland and wellington offices of BCHF. 

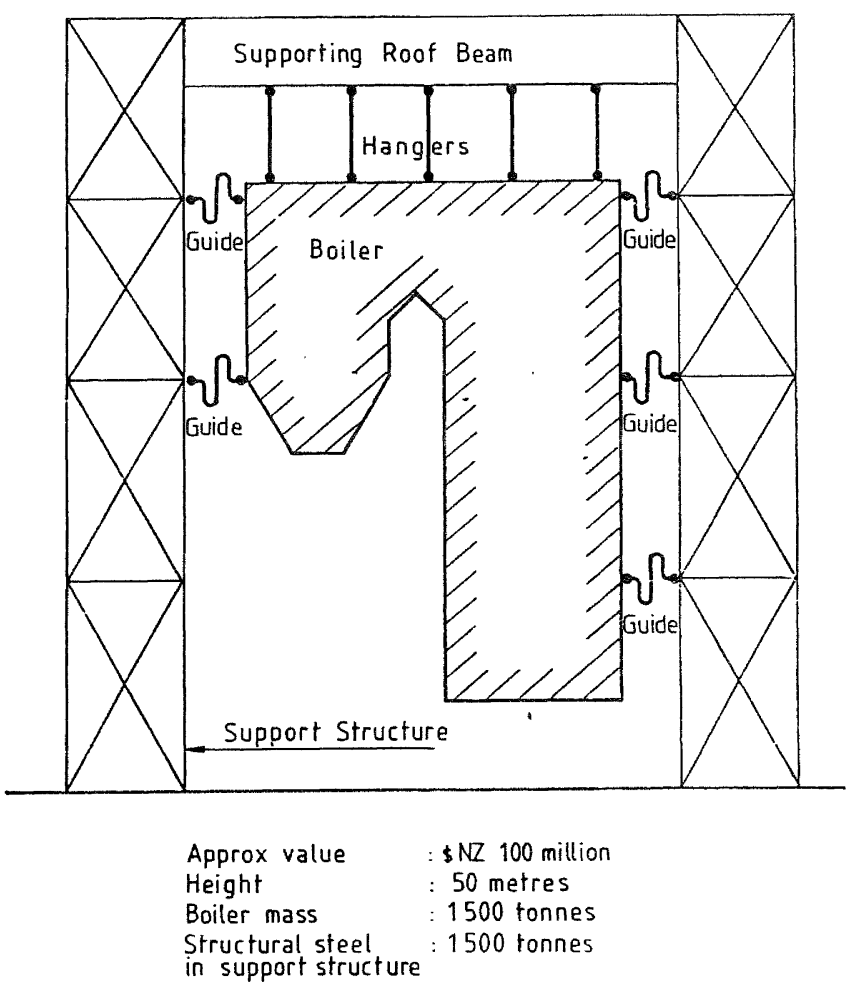

FIG. 1 - DIAGRAM TO ILLUSTRATE STRUCTURAL LAYOUT

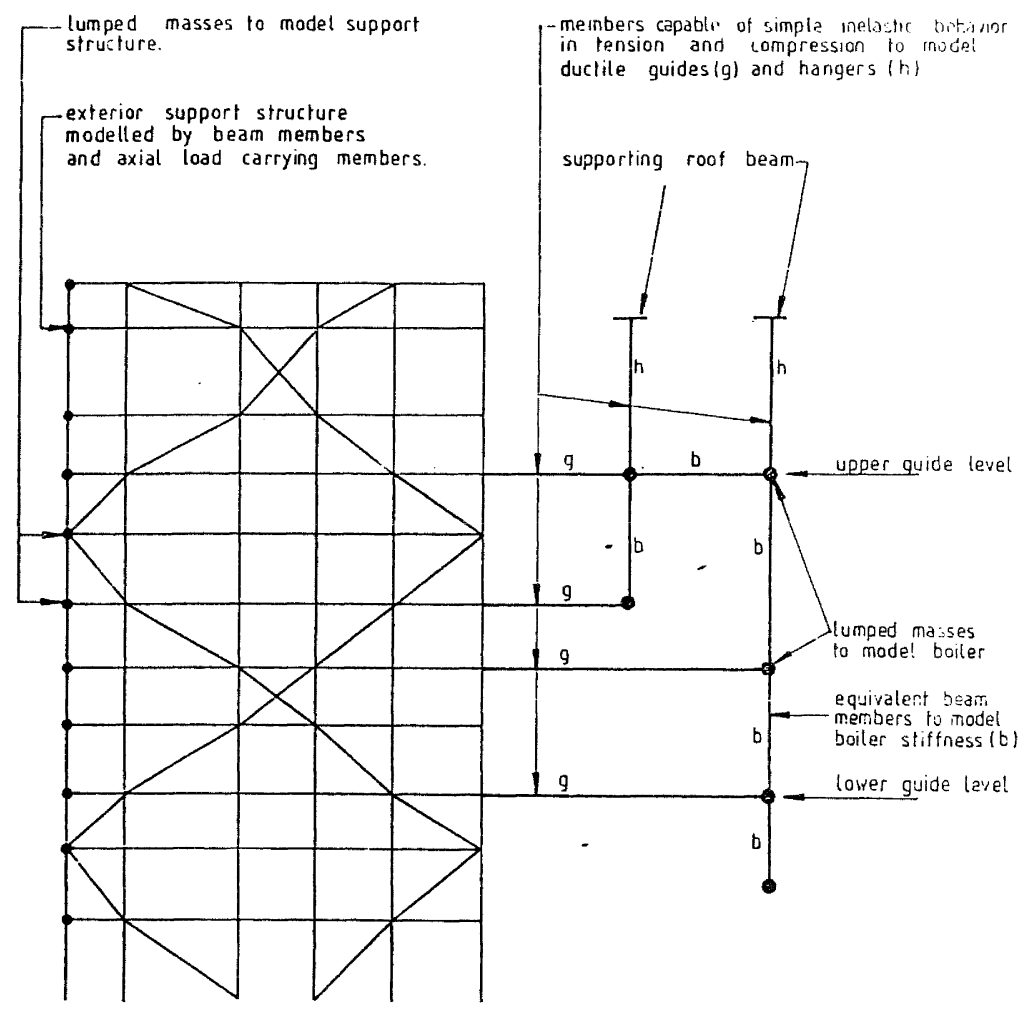

FIG. 2 - TWO DIMENSIONAL ANALYTICAL MODEL OF EXTERIOR FRAME, BOILER AND GUIDES 


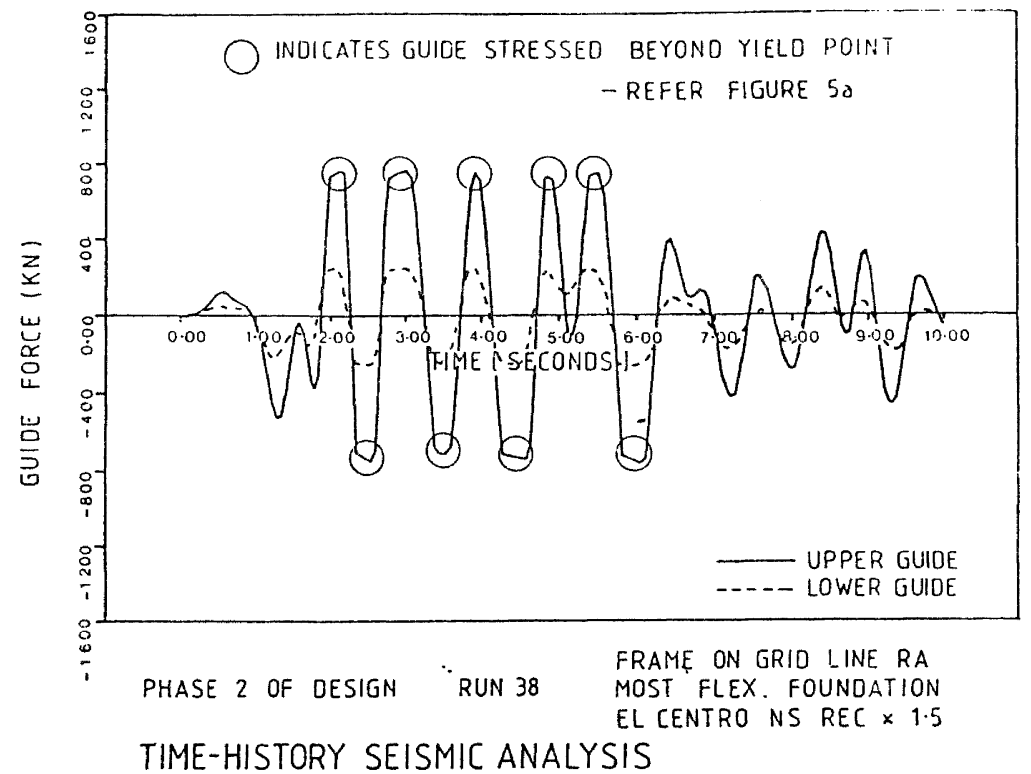

FIG. 3 - FORCES IN TOP AND BOTTOM BOILER GUIDE MEMBERS

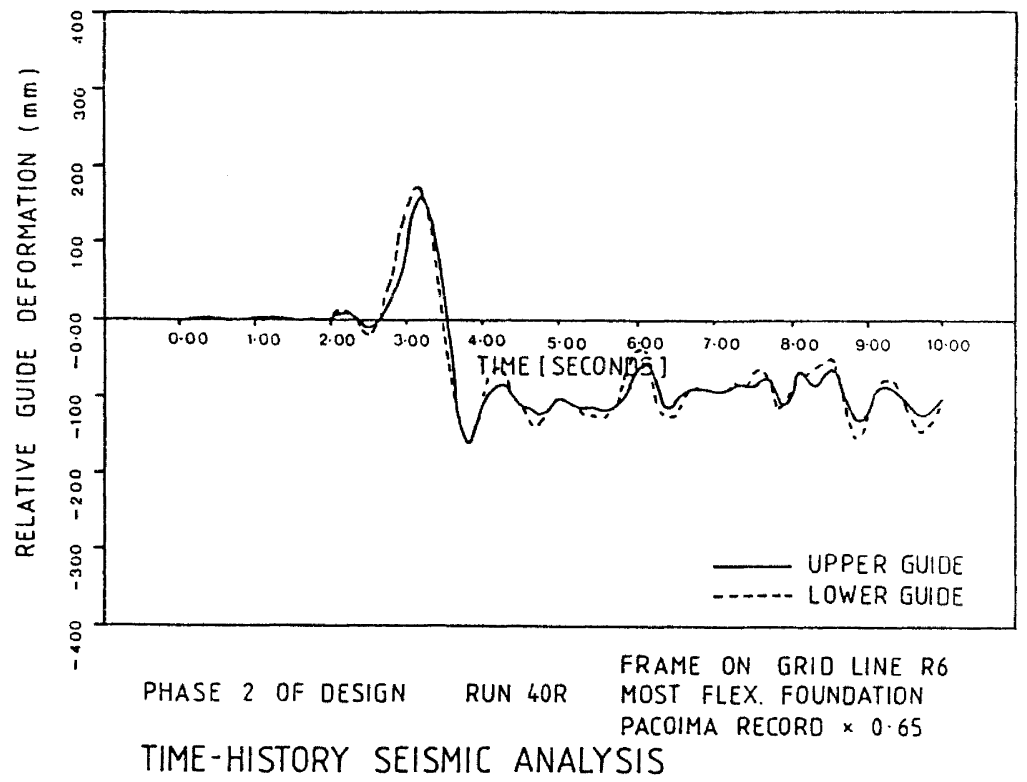

FIG. 4 - DEFLECTION OF TOP AND BOTTOM BOILER GUIDE MEMBERS RELATIVE TO BOILER (This is also deflection of support frame relative to boiler at the guide point) 


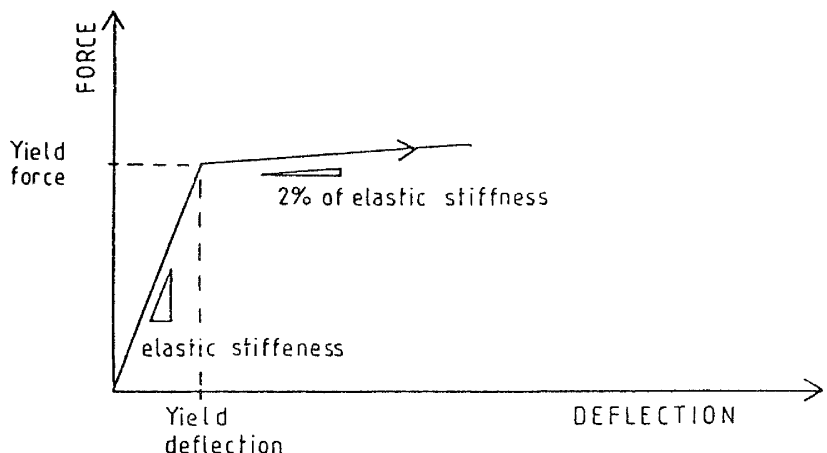

FORCE VERSUS DEFLECTION FOR GUIDE BEAMS

AS USED IN ANALYSIS

Figure $5 a$

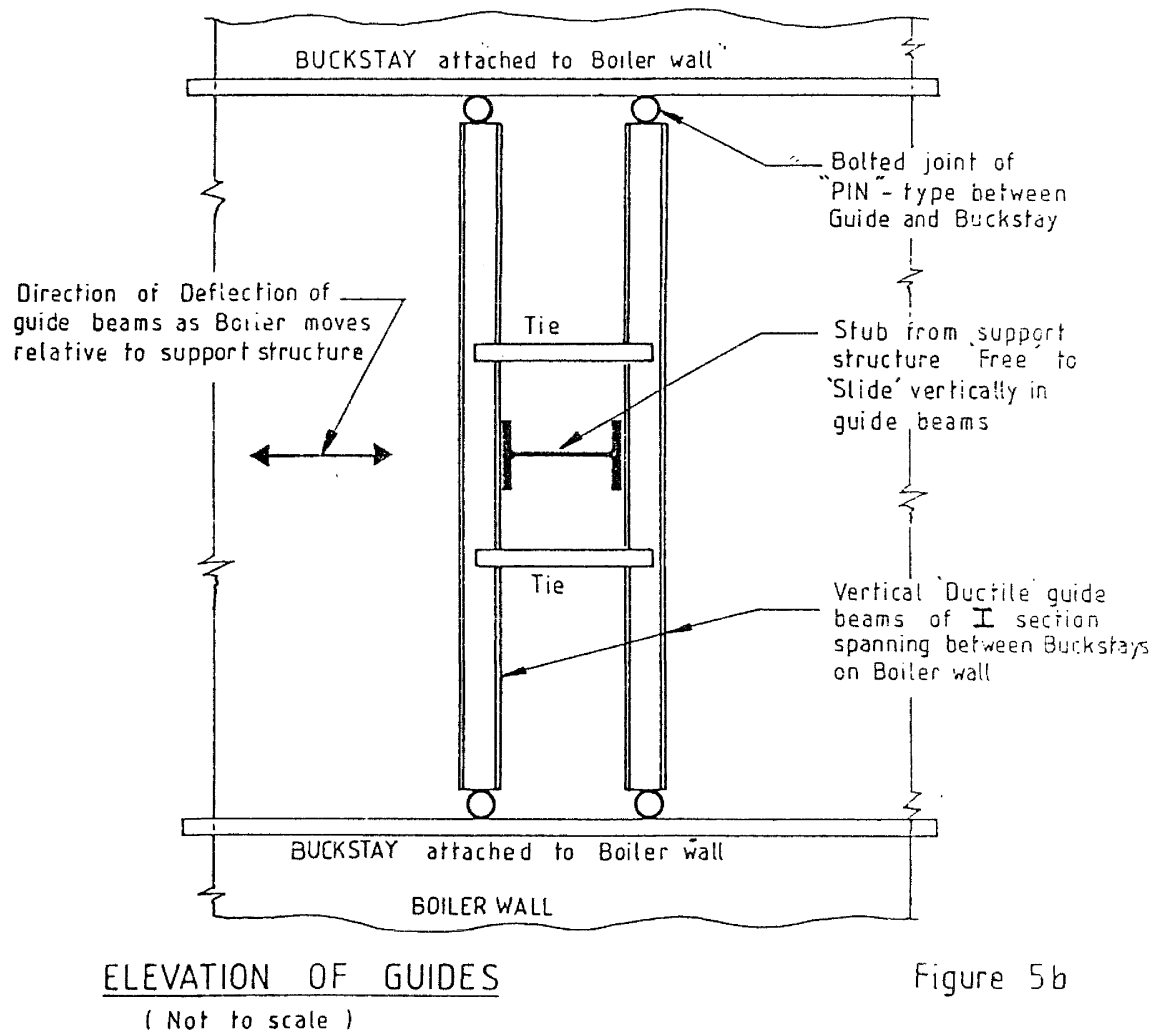

FIG. 5 - GUIDE PHYSICAL CHARACTERISTICS 